\title{
在中国青少年阶段开展财商教育的可行性分析
}

\author{
赵静
}

上海师范大学青年学院

DOI:10.32629/mef.v1i2.28

[摘 要] 作者在财商教育领域一直跟踪研究, 希望能够通过建立完善的教学体系和培养方式, 将《财商教育》引入低年龄阶段 孩子的日常学习中。本文作为综述类文章, 试图将财商的概念介绍清楚, 将财商教育的重要性和可行性分析出来, 并在一定实践 的基础上呼吁国家重视对青少年儿童的财商培养。

[关键词] 财商; 财商教育; 青少年

\section{1 财商的概念}

1. 1 财商

财商, 即金融智商, 指的是 $\mathrm{FQ}$, 它包含了一个人对于财富 的认知、创造和管理。随着社会经济的发展和人们对于财富 的认识, 财商已经成为了人们在现代化国家生存必不可少的 基本素质。

\section{2 财商教育}

财商包括观念 (想不想)、知识 (怎样想)、行为 (怎样做) 三个层次, 是让一个人拥有驾驭金钱, 并且掌握金钱运作规律 的能力, 如同我们所说的智慧理财能力。观念, 即想不想, 是指 人们对于金钱的理解, 对于财富和创造财富的理解。知识, 即怎 么想, 是指在投资和驾驭金钱的过程中积累的见解及知识。行 为, 即怎么做, 是指观念和知识在一定条件下满足了实施要求 并采取的一些行动。观念、知识还有能力共同促进了财商概念 的形成和发展。而人们对于财商教育的理解, 实际上就是对理 财能力的理解, 对投资的理解, 对理财智慧和能力的理解。

\section{2 财商教育的重要性}

在商品经济时代, 人们的理财能力已经成为现代化生活 必不可少的能力之一。对于还在成长的孩子们而言, 财商教 育还十分陌生。因此, 国家和社会, 学校和家庭需要意识到财 商教育的重要性, 这也是国家和社会对孩子们未来经济生活 提出的基本要求。

\section{3 犹太人的财商教育简介}

犹太人在财商教育领域做出的成就最大, 他们认为, 对 孩子进行财商教育, 以及进行延后享受理念的宣传十分重 要。延后享受观念就是指在现阶段努力奋斗, 以获取未来时 间段的享受。犹太人商业成功的秘密在于教育, 而延后享受 则是犹太人教育的核心。犹太人是这样教育小孩的: “如果 你喜欢玩, 就需要去赚取你的自由时间, 这需要良好的教育 和学业成绩。然后你可以找到很好的工作, 赚到很多钱, 等赚 到钱以后, 你可以玩更长的时间, 玩更昂贵的玩具。如果你搞 错了顺序, 整个系统就不会正常工作, 你就只能玩很短的时 间, 最后的结果是你拥有一些最终会坏掉的便宜玩具, 然后 你一辈子就得更努力地工作, 没有玩具, 没有快乐。”这是延 后享受的最基本的例子。
在犹太人的财商教育过程中, 主要体现了现代社会的价 值。也就是说, 人的终极目的是为了终生幸福, 而要实现这个 目标, 就需要立刻进行有计划的合理的人生规划, 主要规划 所用资源, 如金钱等。在犹太人的财商教育中, 青少年必须进 行财商教育, 必须培养掌钱能力、赚钱能力和必须完成财富 知识积累工作。

\section{4 国外儿童财商教育的启发}

4. 1 理财价值观的奠定

现如今, 国内外的财商教育培训班已经十分多, 这些培训 班为了满足人们的实际功能需求, 主要进行理财知识讲解, 并 且教导学生如何进行有效投资和储蓄。香港理财专家周翠珊 女士对此评价: “财商教育最重要的还是观念的教育, 那就像 是内功心法, 心法没练好, 再多的招式都是徒劳无功的。” 我国 中小学生的价值观的形成有赖于此阶段的引导与教育, 若果 在学生的中小学阶段就让其接受财商教育, 对学生未来的影 响将十分巨大, 且能够帮助学生养成良好的财商观念。

\section{2 学校财商教育的开展与完善}

由于财商教育的重要性, 学校应该成为青少年学习培养 财商的主要阵地。目前, 美国、瑞典、丹麦等国的中小学校 都开设了有关财务知识的课程, 带领孩子认识金融世界, 学 习财务开支、企业投资、股票债券等方面的知识。瑞典小学 教材中有涉及商品社会的教育内容; 丹麦的初中教学大纲中, 要求学生掌握申报个人所得税的内容, 并须注明收入的来 源。而相比较于其他国家, 目前我国学校的理财教育还相当 落后。财商教育应当尽早成为正规学校课程的核心部分, 而 其课程可以采用不同的形式, 比如参与市场考察, 引导孩子 利用网络搜索相关资料, 目前, 许多青少年培育网站都有青 少年银行、虚拟交易市场供孩子们进行虚拟理财管理。授课 教师应当充分的了解目前的网络技术, 利用网络虚拟市场进 行财商教育, 了解金融知识和相关教学方法的重要性, 以教 授学生金融知识。

\section{3 理财教育序列要有不同的针对性}

不同年龄段的孩子在接收财商教育的过程中应当使用 不同的计划, 并且还需要根据孩子的心理发展进行计划的调 整。学校在进行财商教育的过程中, 应当使用正确科学的教 
育方法, 循序渐进的完成财商教育工作。我们可以通过借鉴 国外成功的教育模式, 以此完成对孩子们财商教育的目标。

4.4 家庭、学校、社会协调配合财商教育

由于家庭的耳濡目染, 父母最为财商教育最重要的环节, 是孩子们财商观念形成和践行的引导者和榜样, 而孩子们的 财商观念的社会化行为又离不开社会力量的支持和引导。孩 子们的消费观念, 理财意识等能力的形成有赖于整体环境的 促进与影响, 因此, 构建家庭、学校和社会的整体财商教育环 境, 对于孩子理财教育十分重要, 且有利于良好理财教育循 环系统的形成。

\section{5 对国内财商教育现状的思考和建议}

国内财商教育贫乏, 我国青少年财商教育工作进展还十 分缓慢, 远不及国外发达国家的教育水平。其次, 在财商教育 过程中, 主要还是依靠培训机构、根据市场需求来设定的, 而政府对此重视程度还不够。

对国内财商教育普及的几点建议, 全面重视, 立体培养模式

(1) 政府层面: 将青少年财商教育纳入国家教育体系

我国教育部应当高度重视孩子们财商教育, 尽快的研究 并制定出详细的财商教育文件, 文件内容应当指引各学校如 何开展财商教育, 财商教育的内容是什么等。将财商教育当 做国家教育的重点内容之一, 有利于财商教育工作在各学校 的开展。

(2) 社会层面: 通力合作完善我国青少年财商教育体系

社会各方面应当加强孩子们的财商教育工作, 并充分的 发挥出孩子们的自身优势, 积极投入到财商教育的整体环境 构建中。社会中的金融机构还可以与学校进行合作, 如组织 学生到金融机构参观, 引导孩子们进行金融产品的理解。各 专家学者可以就财商教育开展讨论会议, 从学术的角度研究 财商教育的方法, 引导学校开展合理科学的财商教育工作。

(3) 学校层面: 开展青少年财商教育

5.1 加强青少年财商教育的师资建设

5.2 培养学生对财商教育的认知, 使其意识到财商教育 的意义及重要性

5.3 开发符合学生生理和心理发展阶段的财商教育课程

\section{6 建立分年龄段的正确理财思维培养模式}

(1)幼儿阶段: 认识钱的来源和用途

6.1 家长可以和孩子一起上早教理财课 (3-5 岁)。在课 程中, 阅读一些儿童财商启蒙教育读本——— 《穷爸爸, 富爸 爸》、《小狗钱钱》、《神探贝妮、威力哥哥与金融行动》等, 让宝贝获得最基础的理财知识。

6.2 和孩子一起制订一个经济活动的花费预算 (6-7 岁)。例如, 通过举办一个家庭活动, 让孩子参与到家庭活动 开销的制定过程和管理过程中, 对所需要计算的过程进行了 解和参与, 通过实例促进孩子们快速了解理财知识。
（2）小学阶段：通过做一些公益活动或者是公共事务来 换取零用钱, 如洗碗、扫地等。其次, 和孩子们共同制定报酬 清单, 以此调动孩子们的参与积极性和培养孩子们的理财理 念。其次, 和孩子们共同商定零用钱的额度和使用权限, 保证 零用钱的使用具备合理性。在计划零用钱的过程中, 孩子们 会在一定程度上克制自己的消费冲动, 以此锻炼孩子们做事 的计划能力。家长还可以和孩子们一起申领儿童银行卡, 帮 助孩子们熟悉银行财产管理流程, 树立正确的金融意识和消 费记录习惯, 以此引导孩子们正确消费, 计划消费。

(3) 初中阶段: 学会记账管好钱

6.3 和孩子们制定一个短期的旅行计划 (13 岁), 将旅行 开销管理任务交给孩子, 以此提高孩子的旅行预算能力, 金 钱管理能力和计划意识。

6. 4 和孩子们共同选择一个合适的家庭保险 (14、15 岁), 并让孩子们了解保险的内容, 可以帮助孩子理解什么是保 险、为什么要投保、需要购买哪些保险产品等相关知识, 为 其以后正确购买保险打下了良好的基础。

6.5 帮助孩子们开设属于自己的投资账户 (16 岁)。目前, 我国部分银行可以提供亲子成长账户, 是为 18 岁以下的孩 子量身定做的, 例如花旗银行。在开设孩子们的投资账户时, 孩子们可以通过账户进行简单的存储业务, 还可以进行证券 投资等。家长们可以让孩子们通过小额投资, 以此锻炼孩子 的理财能力。

总而言之, 我们需要在借鉴国外财商教育方式的同时, 从我国财商教育的实情出发, 根据不同年龄段孩子的财商教 育情况, 为不同年龄段的孩子提供合适科学的财商教育。同 时, 在做好孩子们财商教育的同时, 还需要做好正确价值观 培养、智商培养和情商培养等工作。

\section{7 结束语}

本文作者利用课余时间, 带领研究生团队, 认真根据孩 子的年龄认知, 开发了系列财商课程, 希望孩子们建立完整 的财商思维模式。

[参考文献]

[1] 封梦媛.英美青少年财商教育现状对我国教育的启示 [J].江西广播电视大学学报,2018,20(01):64-71.

[2]王顺粗.核心素养教育背景下的财商教育路径探究 [J].才智,2017,(18):144-145.

[3]单炳元. 加强青少年财商教育刻不容缓 [J]. 金融经 济,2016,(18):112-113.

[4]李婧萌.浅议青少年金融理财服务 [J]. 经贸实 践,2016,(23):78.

作者简介：

赵静(1977--), 汉族, 山东东营人, 法学博士, 经济学副教 授, 研究方向: 资本市场制度研究。 